\title{
A Logical Framework for the Design, Construction, and Rehabilitation of Mine Site Waste Rock Dumps
}

\author{
R.J. Loch Landloch Pty Ltd, Australia \\ S.M. Lowe Minara Resources Ltd, Murrin Murrin Nickel Operation, Australia
}

\begin{abstract}
Waste rock dumps are a major consequence of many mining operations. Government, community and stakeholder expectations for the rehabilitation of waste rock dumps are continuing to evolve. This places increasing pressure on companies to ensure that their "waste disposal" is as cost-effective as possible, with concerns not only for initial costs, but also for the costs of repair of remediation failures.
\end{abstract}

Pending changes to guidelines for Environmental Performance Bonds for waste rock dumps in Western Australia are expected to adopt a risk-based assessment of the landforms to set bond levels. While such bond guidelines could obviously increase the bond held over high-risk landforms, it could also create potential for well-designed and well-constructed waste rock dumps to be subject to lower levels of bond, further increasing economic incentives for companies to adopt waste rock dump design and construction procedures that will consistently deliver quality, cost-effective results.

This paper outlines (with examples from a number of sites) a framework covering the various stages in design, construction, and rehabilitation of a waste rock dump. Properly applied, the framework can deliver consistent reductions in risk of failure, and dramatic improvements in cost-effectiveness.

Based on the key performance indicator (KPI) approach developed at Minara Resources' Murrin Murrin Nickel Operation (Loch et al., 2006), the framework specifies stages of planning, construction, and rehabilitation, and identifies the range of actions necessary within each stage. The framework is distinctive for its emphasis on quality control during waste rock dump construction, but this aspect of waste rock dump construction is crucial to achievement of a quality outcome. Similarly, the framework specifies a range of actions for planning and executing dump rehabilitation works.

\section{Introduction}

Waste rock dumps are a major consequence of many mining operations. Government, community and stakeholder expectations for the rehabilitation of waste rock dumps are continuing to evolve. This places increasing pressure on companies to ensure that their "waste disposal" is as cost-effective as possible, with concerns not only for initial costs, but also for the costs of repair of remediation failures. Industry figures for the costs of repairing rehabilitation failures are rarely made public, although one example is the capping and remediation of three-failed waste rock dumps covering 42 ha at the Rum Jungle mine for a cost of $\mathrm{A} \$ 16.2 \mathrm{M}$ in 1983-6 (Taylor et al., 2003).

Pending changes to guidelines for Environmental Performance Bonds for waste rock dumps in Western Australia by the governing body, the Department of Industry and Resources (DoIR), are expected to adopt a risk-based assessment of the landforms to set bond levels will be implemented. This could create potential for well-designed and well-constructed waste rock dumps to be subject to lower levels of bond, further increasing economic incentives for companies to adopt progressive mine rehabilitation, least risk waste rock dump design, and construction procedures that will consistently deliver quality, cost-effective results.

This paper outlines a framework covering the various stages in design, construction, and rehabilitation of a waste rock dump. Properly applied, the framework can deliver consistent reductions in risk of failure, provide dramatic improvements in cost-effectiveness, and enhance the company's marketability of its level of environmental management via its stakeholders. This last point must not be over-looked as the DoIR have 
stated recently that future mining approvals will be based upon what they see as the perceived level of excellence shown by the company's environmental management and performance.

\section{$2 \quad$ Underlying strategy}

Guidelines for the construction of waste rock dumps have two options, to either:

- Adopt a prescriptive approach and specify specific landform attributes, such as berms, rock drains, batter angles.

- Set out a framework for dump design and rehabilitation that will be consistently effective.

Historically, waste rock dump design in Western Australia has followed the first option above, and the results have not been encouraging. Materials used in dump construction vary enormously, as does climate. Consequently, although specified landforms have - on occasion - been successful, there are widespread observations of tunnel erosion and gullying, evidence that the prescriptive approach has, in many cases, been a major cause of instability. Initial waste dump rehabilitation at the Murrin Murrin Nickel Operation (MMO) using prescribed designs showed consistent failure (Landloch Pty Ltd and Rally Revegetation and Environmental Services, 2004).

The alternative - to develop a framework to guide waste rock dump design, construction, and rehabilitation has had limited application on Western Australian mine sites. Ideally, the framework should ensure that all relevant steps/actions are followed, without pre-empting any design decisions that may become necessary. As such, it should spell out the logical and necessary considerations that are part of waste rock dump planning, construction and rehabilitation. Importantly, each mine site should consider and adapt the framework so that it applies specifically to their unique conditions.

Recent experience at MMO has demonstrated the successful application of a logical design framework. The site has developed key performance indicators (KPIs) to track waste rock dump rehabilitation (Loch et al., 2006). The KPI process provides quantitative, objective and repeatable evaluations of rehabilitation, with ability to tailor rehabilitation activities to the specific needs and risks of individual areas. This approach was adopted to create certainty for rehabilitation requirements and responsibilities and in the potential for bond return or reduction, but it also provides a basis for waste rock dump planning. The KPIs were developed to cover five broad sequential areas:

- Planning.

- Construction.

- Initial Performance.

- Monitored Performance.

- Sustainability.

For waste rock dump design and rehabilitation, the initial three areas are key to success. The approach used in developing the KPIs was to work from the general to the specific, with the specific tasks identified being relevant to the site. For MMO, each of the above five broad areas is broken down into key elements, then further divided into specific tasks, with each specific task having a range of quantitative or objective indicators of completion.

\section{$3 \quad$ Planning}

This approach explicitly recognises that planning is essential. For MMO, planning is divided into key tasks of:

- Characterisation of soils, wastes, and the prevailing climate.

- Definition of goals for the rehabilitated landform.

- Preparation of landform design.

- Identification of plant species required. 
- Assessment of soil fertility needs and amendments.

This phase should be completed prior to any construction of the waste rock dump. Obviously, for many sites, where material properties are reasonably consistent, this initial planning phase can be used to develop standard operating procedures (SOPs) for waste dump construction and may not need to be repeated in detail for each pit and waste rock dump.

\subsection{Characterisation}

Characterisation of soils, wastes, and of the prevailing climate can not only identify threats to landform sustainability, but also provides important information to underpin all other components of the planning process.

\subsubsection{Avoidance of problems}

Apart from concerns with sulphidic materials, the most common problems encountered are salinity, sodicity, and extremes of $\mathrm{pH}$.

Salinity is a widespread concern within the goldfields region of Western Australia, and it is possible to identify a number of waste rock dumps that were constructed and repeatedly (unsuccessfully) topsoiled and seeded before their high salinity was realised. Sodicity is also common on Australian mine sites, contributing to tunnel erosion, failure of engineered structures, and widespread gullying. However, risks of tunnel erosion are not confined to sodic and dispersive materials, and a somewhat wider range of materials have potential for tunnel erosion. Extremes of $\mathrm{pH}$ are less common, though by no means rare, but have potential to strongly impact on vegetation growth and establishment.

A range of other issues are possible, including micro-nutrient toxicities.

\subsubsection{Understanding local ecosystems}

The combination of data on soils, landscapes, and climate can be extremely important in understanding how ecosystems work, and thereby, how effective ecosystems can be created by rehabilitation.

For example, surface soil (0-100 mm depth) under open woodlands in central Queensland would typically contain approximately 3\% organic carbon. Assuming a bulk density of $1.3 \mathrm{~g} / \mathrm{cc}$, the surface $100 \mathrm{~mm}$ deep layer of soil will contain $39 \mathrm{t} / \mathrm{ha}$ of carbon, and $3.9 \mathrm{t} / \mathrm{ha}$ of nitrogen. For rehabilitated soils on mine sites, total $\mathrm{N}$ can be as low as $0.05 \%$, equivalent to $0.65 \mathrm{t} / \mathrm{ha}$ of $\mathrm{N}-$ some $3.25 \mathrm{t} / \mathrm{ha}$ less than in the same layer of undisturbed sites. These data bring into sharp focus the need (for that area) to:

- Manage topsoil stockpiles so that organic carbon (and N) are maintained.

- Establish ecosystems that will gradually accumulate N.

- Avoid managing rehabilitated areas in ways that will reduce potential for, or rates of, $\mathrm{N}$ accumulation.

In another example, work on an arid zone site found that the local vegetation relied on water stored up to $5 \mathrm{~m}$ deep in the soil, yet water balance models clearly showed that water penetration below $0.5 \mathrm{~m}$ depth appeared unlikely. Subsequent review of the data and the site found that the presence of microphytic crusts was linked to high levels of spatial heterogeneity in infiltration, thereby enabling water to move to considerably greater depth. As well, a specific soil layer at depth was found to be a key water storage zone. Based on that understanding, rehabilitation could then be planned to re-develop a functional soil profile and ecosystem for that area.

\subsection{Setting goals}

Goals for a landform can vary widely, depending on the intended final land use, and will typically require input from a range of stakeholders. However, it is important that the goals set should be realistic and achievable, and information on climate and soils/wastes is crucial in guiding discussions. It is important that goals be identified and agreed early in the design process. 


\subsection{Landform design}

\subsubsection{Height}

A wide range of landform design issues could be considered, but one of the primary concerns is specification of final landform height. For most materials, it is possible to define a maximum batter height that will be stable, with roughly the same height applying across a wide range of batter gradients. Such information can only be derived via erodibility measurements and erosion modelling, so the maximum height identified is dependent on both climate and assumptions of acceptable erosion rates. Nonetheless, definition of a stable landform height is a crucial first step in landform design considerations.

It is not uncommon for the stable height identified to be too low to be practical for mine site purposes. In those cases, additional "support" practices may be necessary to achieve a desired landform height whilst maintaining appropriate levels of erosion stability. This can allow mine planners to consider the cost of e.g., specific placement of a non-erosive waste - relative to the cost savings associated with an increase in overall landform height. Obviously, this is an area where considerable flexibility and creativity is possible.

\subsubsection{Outer batter profiles}

The outer batters of a constructed landform are usually not only the most costly part of a landform to rehabilitate, but also the part of the landform most crucial to its success or failure. Consequently, batter slopes are typically subject to considerable design effort. As with landform height, once a stable profile is identified, a range of other issues can then be considered.

Design of a stable batter slope profile is typically done using an erosion model, so that a unique solution tailored to the specific climate and materials is developed. There is no scientific justification for widespread application of a given batter profile across a range of materials and climates. Figure 1 shows an example of erosion simulations for a batter slope at $\mathrm{MMO}$, with consideration of the impacts of levels of contact cover by tree debris. Figure 2 shows the areas on the slope designated for placement of $20 \%$ tree debris cover on the basis of that modelling, thereby enabling strategic placement and use of a very limited resource.

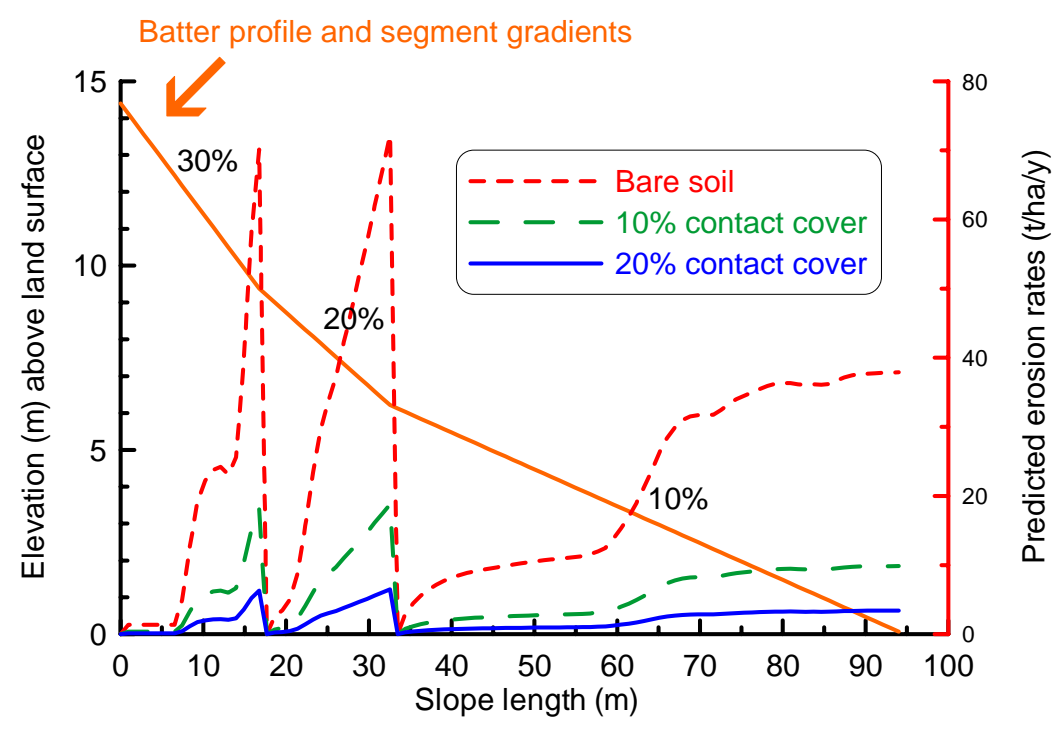

Figure 1 Erosion model output for a concave profile, MMO 


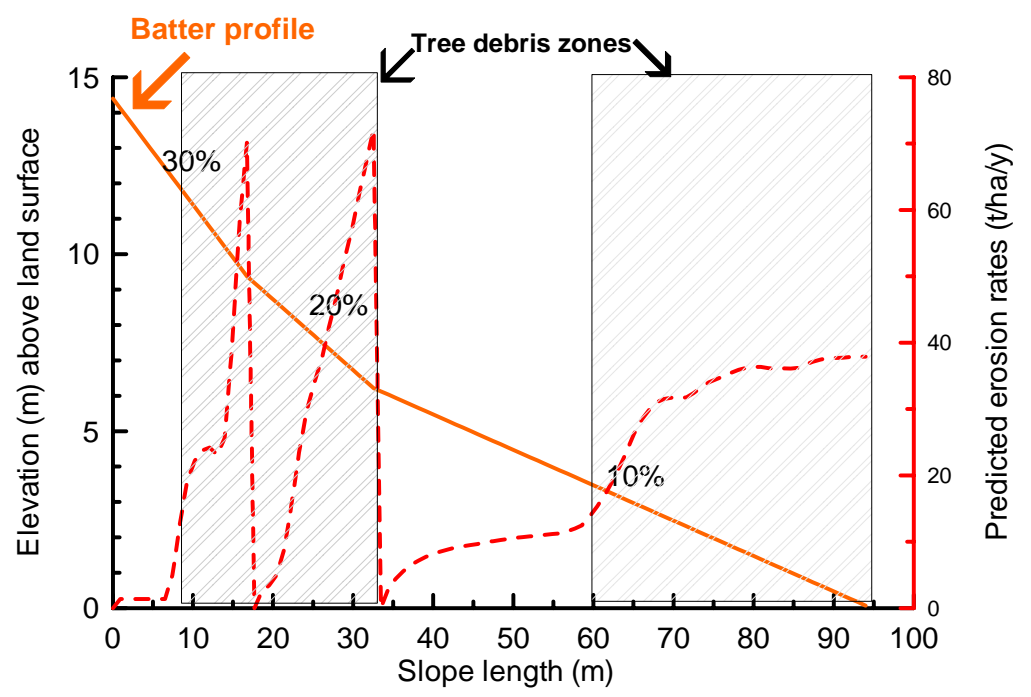

Figure 2 Zones for tree debris placement based on erosion model output, MMO

Importantly, planning for landform construction should also consider the final costs of rehabilitation. For example, correct initial spacing of lifts can drastically reduce the costs of final shaping, by reducing not only the volumes to be moved, but also the distances of push (Figures 3 and 4). For Figure 4, the cross-section shows that the quantity of material to be moved can be greatly reduced by strategic placement of lifts - from 120 to $77 \mathrm{~m}^{2}$ approximately. Importantly, the set-back between the two lifts can be set so that the quantities of cut and fill are balanced for each lift, thereby minimising the distances of push. For a square 20 ha waste dump, with perimeter of approximately $1800 \mathrm{~m}$, adoption of the Figure 4 layout would reduce total material movement during re-shaping relative to that shown in Figure 3 by $76,680 \mathrm{~m}^{3}$. If assuming a cost for material movement of $A \$ 0.70$ per $\mathrm{m}^{3}$, then the reduction in volume of cut-and-fill translates to a saving of $A \$ 53,676$, with likely additional benefits from reducing the distance of push. Similarly, there are obvious cost penalties if the space between lifts is too large.

Although the focus of landform design inputs at MMO was to reduce off dump erosion and topsoil loss (Landloch Pty Ltd, 2004, 2005, 2006), Figures 3 and 4 demonstrate the added benefits that have been identified through potential for construction savings. Further quantification of the measured results and performance will be available following this year's current regime of waste rock dump rehabilitation which will allow comparative analysis of the methodology and the cost savings associated with this strategy against previous dump construction and rehabilitation.

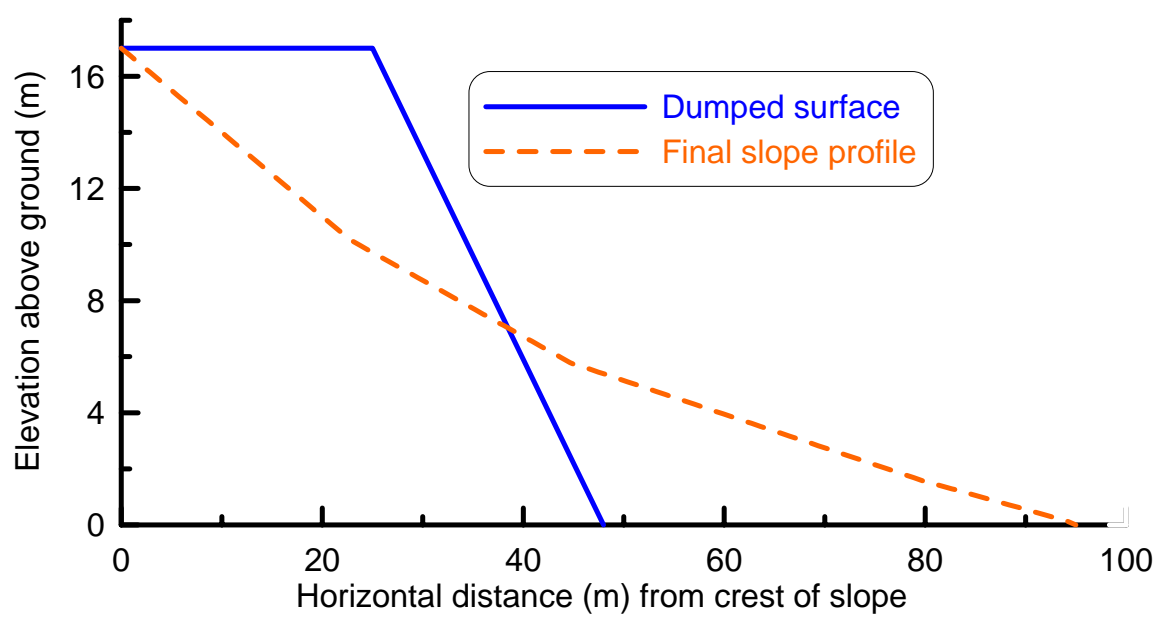

Figure 3 Comparison of initial and final profiles where material is not dumped in strategically placed lifts - for concave profile developed for MMO waste dump rehabilitation 


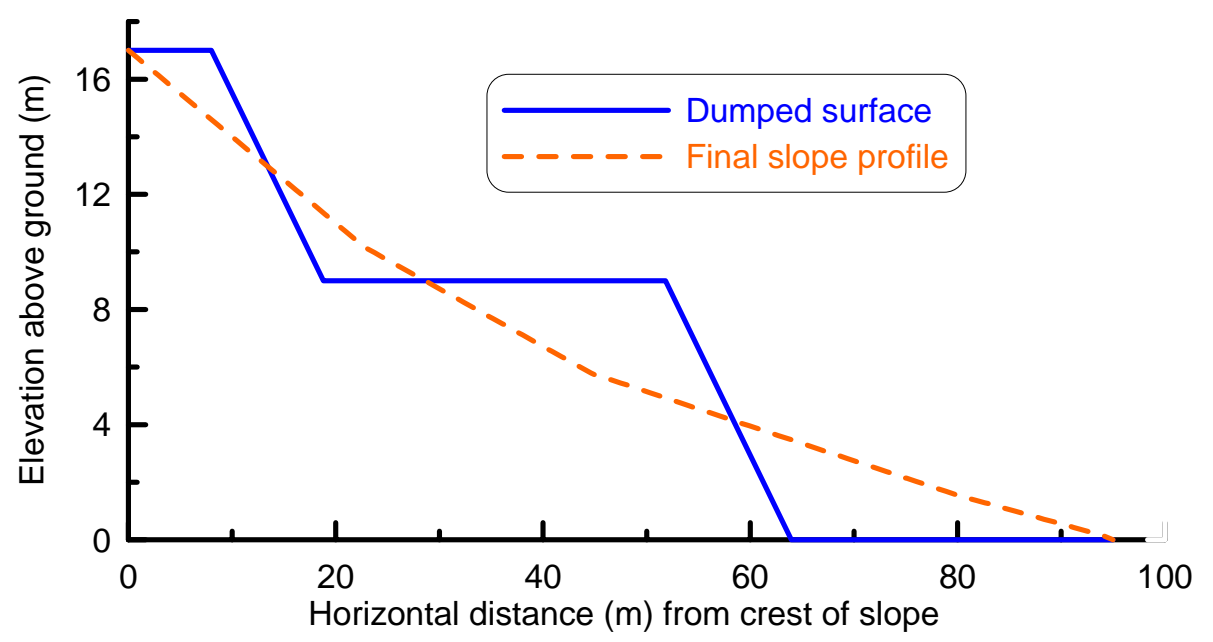

Figure 4 Comparison of initial and final profiles where lifts are strategically placed to balance and reduce cut-and-fill

\subsection{Amendments and fertiliser}

Amendment and fertilisation can be guided by soil/waste analysis, and have potential to give dramatic improvements in vegetation establishment. Fortunately, requirements for amendments at MMO are not pressing, as sodicity and acidity are of limited concern.

Timing of amendments can be crucial. For example, some sites place topsoil of neutral $\mathrm{pH}$ over wastes that are quite acid and hostile to plant growth. In that situation, broadcasting of lime at the time of final ripping and seeding (once topsoil is in place) is totally ineffective, as lime is insoluble when $\mathrm{pH}$ is neutral or alkaline. The only effective approach is to spread and incorporate lime prior to spreading the topsoil.

\subsection{Plant species requirements}

Early recognition of plant species requirements can be crucial in terms of ensuring adequate seed supplies, planning construction of sustainable and productive soil profiles, and confirming that profile hydrology is consistent with the planned ecosystem.

Particularly in arid regions, profile hydrology has an enormous impact on plant ecosystems. For example, species adapted to impermeable rocky ridge tops may be poorly adapted to the top of a waste rock dump constructed using fractured and highly permeable rocky waste.

\section{Construction}

Poor construction ultimately leads to waste rock dump failure, irrespective of the quality of the landform design. For that reason, quality control with respect to landform construction is essential. Specific objectives of the waste rock dump construction process relate to mine planning, topsoil and vegetation management and rehabilitation. At MMO, these are:

- To ensure that best practice, including sampling and material characterisation, is used for all mine planning and rehabilitation development.

- To develop a stable landform compatible with the contiguous landscape, with a non-erodible surface conducive to self-sustaining revegetation.

- To ensure topsoil and vegetation are managed to maintain their viability and usefulness.

- To optimise availability of laterite for rehabilitation purpose.

- To ensure that rehabilitation is completed progressively and to the satisfaction of the DoIR.

- To carry out monitoring to ensure and demonstrate rehabilitation success. 
At other sites, objectives could be expected to vary significantly.

\subsection{Sampling}

Various sampling programmes should be carried out before, during and after pit operations. Initially, topsoils can be analysed prior to mining development to assess topsoil properties after vegetation clearing. A full spectrum analysis should be undertaken. These results provide baseline data and give indications of possible ameliorants required to promote successful revegetation. At MMO, subsequent topsoil testing is carried out prior to the topsoil being reapplied to the newly constructed landform ( 1 month before), giving a clear picture of all nutritional and ameliorant requirements to be included in the rehabilitation programme. The comparison of the initial sample against the final sample shows deterioration proportional to time stockpiled and allows site-specific topsoil stockpiling strategies to be developed.

\subsection{Material characterisation}

Detailed material characterisation and analysis can be undertaken on representative samples throughout the stockpiled waste dump. MMO conducts extensive material sampling, erosion trials including rainfall simulation and computer modelling to determine an appropriate landform design for each waste dump.

Waste characterisation undertaken to date has identified three main types of waste material, which will be mined for the development of pits at MMO:

- Ferruginous cap rock: This material will be stockpiled separately and placed on the outer batters of the waste dump to assist in erosion control.

- Smectite clay: Limited amounts of this material will be mined as waste as the smectite clay predominately comprises the ore at MMO.

- Saprolite clay: The majority of the waste material will consist of saprolite clays.

The nature and characteristics of the overburden and wastes generated from mining activities are such that there are not expected to be any deleterious chemical consequences, such as acid mine drainage, arising from runoff or leaching from the dumps. None of the wastes or overburdens from mining has been identified as containing sulphides to date.

Segregation and selective placement of overburden layers is practised for two key reasons:

- To bury material that is adverse to plant growth or which may contaminate surface or groundwater supplies.

- To salvage materials that will assist in the rehabilitation programme.

Appropriate placement of waste materials in accordance with the rehabilitation design during mining can lead to significant cost savings during rehabilitation earthworks.

Whenever possible and practical to do so, waste dumps at MMO are to be constructed to ensure that inappropriate materials - saprolite and smectite - are disposed of in the centre of the dump with the Ferruginous material being placed on the outer batters of the slopes.

Key tasks identified for control of the landform construction process at MMO include:

- Effective communication and operational understanding of the process by all personnel involved.

- Regular inspections of the on-going construction with quality control checks or inspection test points established for the correct placement/construction of:

o Materials (topsoils, wastes).

o Slope profiles.

o Ripping.

o Seeding.

o Fertilisers and amendments. 
- Appropriate machinery designation and utilisation for the varying requirements associated with each of the construction tasks.

- Waste dump construction will conform to the MMO construction KPIs for rehabilitation success. Completion of and compliance with the KPIs is documented.

- Final checks to confirm conformance of the landform construction to the required design parameters.

- Effective record keeping to log all construction variances that may or may not impact the landform stability over time. Any nuances to the specified design should be noted in an information storage system that is accessible.

Upon construction completion, the rehabilitated area is monitored yearly to quantify the results of the rehabilitation effort. This time frame will increase as the landform and its vegetation community evolves and reaches a state of self-perpetuation and resilience.

\section{$5 \quad$ Monitoring}

Monitoring performs a number of purposes:

- Provides a mechanism to determine the level of rehabilitation success, which has been achieved by the rehabilitation of the landform.

- Reviews the success of the rehabilitation process to determine the suitability of the rehabilitation techniques utilised and promote continuous improvement in rehabilitation methods.

- Initial construction data allow time and motion studies of the performance and overall economics of the construction process. These baseline data are also useful in forward year rehabilitation budgetary planning and in providing raw data for mine closure submissions.

Ongoing prescribed monitoring compares the designed (both modelled and simulated) datasets against the real time stability of the rehabilitated landform. Results provide feedback to further fine tune waste rock dump designs specific to localised site materials and climatic fluctuations.

Accumulated data are used for identifying and improving future design applications along with producing cost effective construction plans that produce landforms that offer long-term stability. Monitoring provides information that specified KPIs have been achieved, thereby enabling the reduction or retirement of bonds held by DoIR against mining disturbance.

Monitoring involves the establishment and monitoring of analogue sites to provide a basis for comparison. Analogue sites are an important part of the monitoring process and should be set up as comparative targets for the rehabilitation prior to the commencement of construction. Analogue sites enable climatic and seasonal changes that may impact on rehabilitation progression to be evaluated (Stingemore, 2007).

Document control of rehabilitation assessment against KPIs and monitoring progress reports is essential. Feedback on the success or otherwise of rehabilitation is to be incorporated into future rehabilitation activities to ensure continual improvement of the rehabilitation process.

Should monitoring indicate that the required level of rehabilitation success is not being achieved, the need for remedial action is to be assessed and undertaken if deemed necessary.

\section{Sustainability}

Sustainability is the final stage of the rehabilitation process and is dependent upon the monitoring information gathered in the KPI process. To achieve sustainable development, considerations include, environmental aspects, ongoing stakeholder engagement and regulatory requirements.

Typical indicators include, but are not limited to: the level of weed and grazing control, plant cover (its density, variety and fecundity), that the rehabilitation meets completion criteria and most importantly, the continued minimisation of risk to the DoIR. 


\section{Overview}

Important aspects of this framework are that:

- The landforms designed are uniquely adapted to the properties of the materials used and the local climate.

- The designs are underpinned by runoff and erosion modelling to provide a defensible and transparent design process.

- The rehabilitation practices used and the goals set for the landforms are consistent with the properties of the materials used in construction of the landforms.

- The construction process is optimised to reduce cost of final rehabilitation works.

- The final rehabilitation work incorporates detailed quality control steps.

- Subsequent monitoring provides feedback with respect to the success of design and construction methods.

- The KPI process ensures that the various steps in the process are consistently followed and documented.

Few things in life are guaranteed, and certainly not the successful rehabilitation of mine site waste rock dumps. However, the process adopted by MMO does guarantee that logical and scientifically sound procedures will be followed during the design, construction, and rehabilitation of waste dumps, thereby reducing the risk of failure to the lowest possible level whilst enabling the potential of early unconditional bond relinquishment.

\section{References}

Landloch Pty Ltd (2006) Generic Concave Slope Profiles for Constructed Landforms, Murrin Murrin Nickel Operation, not Published.

Landloch Pty Ltd (2005) Field rainfall simulator and overland flow study of batter slope erodibility: development of stable slope profiles for Minara Resources Murrin Murrin Operations, not Published.

Landloch Pty Ltd (2004) Erodibility of materials from Murrin Murrin Operation, Minara Resources: Results of laboratory studies, and computer simulations to design stable batter slopes for waste dumps, not Published.

Landloch Pty Ltd and Rally Revegetation and Environmental Services (2004) Rehabilitation and Stability Assessment of Landforms at Murrin Murrin, Not Published.

Loch, R., Stevens, T., Wells, G. and Gerrard, R. (2006) Development of key performance indicators for rehabilitation, Murrin Murrin Operation. Fourie, A.B. and Tibbett, M. (editors), Proceedings First International Seminar on Mine Closure, 13-15 September 2006, Perth, Australian Centre for Geomechanics, pp. 569-576.

Minara Resources (2005) Environmental Management Plan For Murrin Murrin Operations Pty Ltd, Minara Resources.

Stingemore, M. (2007) Rehabilitation Management Plan - Waste Dumps, Minara Environment Department, pp. 34-35, not Published.

Taylor, G.A., Spain, A., Nefiodovas, A., Timms, G., Kuznetsov, V. and Bennett, J. (2003) Determination of the Reasons for Deterioration of the Rum Jungle Waste Rock Cover. http://www.acmer.uq.edu.au/publications/attachments/RumJungleReportJuly2003.pdf.

Vacher, C.A., Loch, R.J. and Raine, S.R. (2004). Identification and Management of Dispersive Mine Spoils Report. http://www.acmer.uq.edu.au/research/attachments/DispersivespoilsreportfinalJune2004R. 